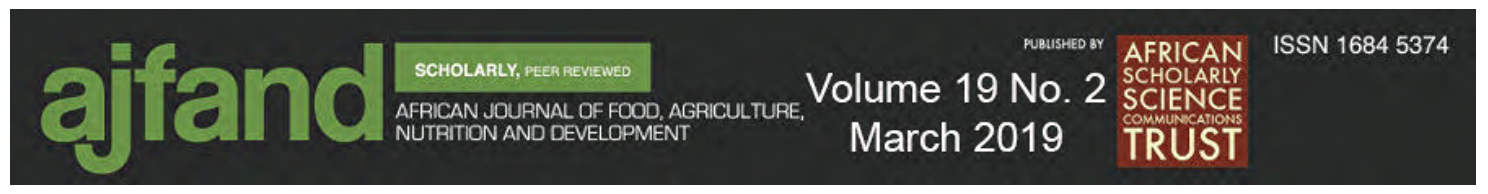

Afr. J. Food Agric. Nutr. Dev. 2019; 19(2): 14218-14243

DOI: 10.18697/ajfand.85.17255

\title{
IODINE STATUS AND SOURCES OF DIETARY IODINE INTAKE IN KENYAN WOMEN AND CHILDREN
}

Bukania $Z^{1}$, Van der Haar $F^{2 *}$, Mwangi $\mathbf{M}^{1}$, Mugambi $G^{3}$, Murage $L^{4}$, Mwai $\mathbf{J}^{3}$, Ng'ang'a $J^{5}$, Kaduka $L^{1}$, Ndemwa $P^{1}$, Wanyoike $C^{4}$ and $Y$ Kombe ${ }^{1}$

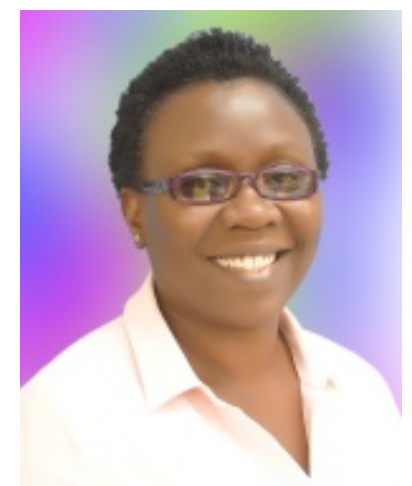

Bukania Zipporah

*Corresponding author email: fvander@emory.edu

${ }^{1}$ Center for Public Health Research, Kenya Medical Research Institute, P.O. Box 54840, Nairobi, Kenya

${ }^{2}$ Rollins School of Public Health, Emory University, 1518 Clifton Rd N.E., Atlanta, GA 30322, USA and Iodine Global Network, Ottawa K1E 3E6, Canada

${ }^{3}$ Nutrition and Dietetics Unit, Ministry of Health, P.O. Box 43319, Nairobi, Kenya

${ }^{4}$ Nutrition International (formerly Micronutrient Initiative), P.O. Box 22296, Nairobi, Kenya

${ }^{5}$ Kenya National Bureau of Statistics, P.O. Box 30266, Nairobi, Kenya 


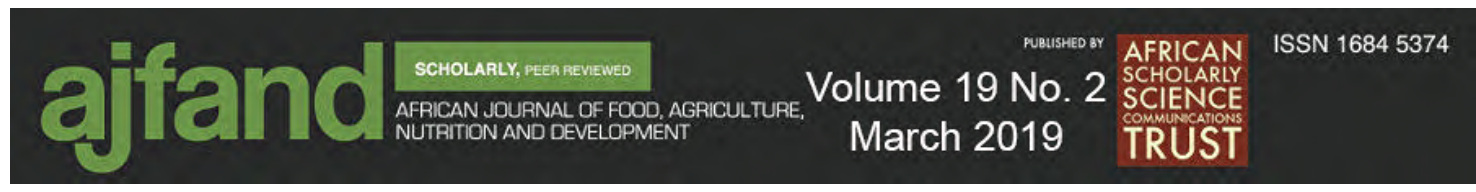

\section{ABSTRACT}

In 2009, the Government of Kenya adopted a mandatory iodine standard for all edible salt of $30-50 \mathrm{mg} / \mathrm{kg}$ with potassium iodate as a required fortificant. To assess the new standard, iodine nutrition measurements were included in the Kenya National Micronutrient Survey (KNMS) in 2011. Spot urine samples were obtained from 951 school-age children (SAC, 5 - 14y of age) and 623 non-pregnant women (NPW, 15 $49 y$ ), together with 625 salt samples from their households. Because salt is the major dietary source of iodine as well as sodium in Kenya, sodium concentrations were measured in the same urine samples. Using the iodine and sodium data, the report introduces a novel regression technique to apportion the urinary iodine concentrations (UIC) in both survey groups to the key sources of iodine intake, namely, naturally present (native) iodine content, iodized salt in processed foods and iodized household salt. The salt iodine (SI) content in Kenya's households (mean $40.3 \mathrm{mg} / \mathrm{kg}$, SD $19.4 \mathrm{mg} / \mathrm{kg}$ ) showed high-quality iodized salt supply. The SI content in $94.9 \%$ of households was $\geq 15$ $\mathrm{mg} / \mathrm{kg}$. Median UIC findings in SAC $(208 \mu \mathrm{g} / \mathrm{L})$ and NPW $(167 \mu \mathrm{g} / \mathrm{L})$ indicated adequate iodine nutrition. Although variations in UIC values existed by age, gender (only in SAC), residence type, household wealth index, and region, median UIC findings were within the accepted optimum range in virtually all sub-categories. The findings do not suggest the need for change in Kenya's universal salt iodization (USI) strategy or adjustment of the current salt iodine standard. Partitioning of UIC values by dietary sources of iodine intake in each survey group attributed $\pm 35 \%$ to native dietary iodine content, $\pm 45 \%$ to processed food and $\pm 20 \%$ to household salt. The UIC levels from native iodine intake alone $(60.8 \mu \mathrm{g} / \mathrm{L}$ and $65.3 \mu \mathrm{g} / \mathrm{L}$ in SAC and NPW, respectively) fell below the threshold for iodine deficiency, which supports the inference that the current USI strategy in Kenya is effective in preventing iodine deficiency. The results from regression analysis indicate that the iodine intakes of SAC and NPW can be explained mainly, and in the same way, by their urinary sodium concentrations $(\mathrm{UNaC})$ and the SI contents in salt from their households. The spot $\mathrm{UNaC}$ data do not accurately represent salt intake estimates but the mean $\mathrm{UNaC}$ findings may be useful for analyzing future changes in salt supply and use from efforts to reduce the salt intake of Kenya's population.

Key words: Universal Salt Iodization, Dietary Iodine Sources, Population Iodine Status, Kenya 


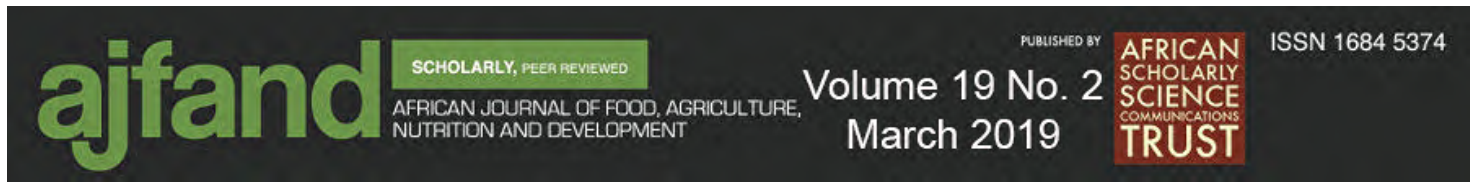

\section{INTRODUCTION}

Iodine is required for biosynthesis of thyroid hormones in the thyroid gland. Since thyroid hormones regulate the metabolism and functions of proteins, carbohydrates, and lipids during all stages of life, insufficient dietary iodine can lead to a variety of serious consequences. Due to rapid growth and specialization of the brain during its early development, the most critical consequence of hypothyroidism due to iodine deficiency is brain damage in the fetus and young infant, which has serious consequences for learning and education of children and their prospects of a future productive adult life [1]. Even mild iodine deficiency may be causally involved in cognitive impairment among children [2]. From data available up to 2011, an estimated 2 billion people worldwide had insufficient dietary iodine intake to meet their physiologic needs. This estimate represents a reduction of $6.4 \%$ from 2007 but still encompasses more than onequarter of the world population [3].

Frequent large goiter occurrence was reported in Kenya as early as the 1920s. The first survey in 1964 reported goiter prevalence ranging between $15 \%$ and $72 \%$, with the highest burden in the highlands of Rift Valley, Nyanza and Western regions [4]. Subsequently, salt iodization was started in 1970 on a voluntary basis, first benchmarked at $20 \mathrm{mg}$ iodine $/ \mathrm{kg}$, which was then revised to $30 \mathrm{mg}$ iodine $/ \mathrm{kg}$ in 1973 . Subsequent studies reported improved urinary iodine levels but this was not accompanied by corresponding goiter prevalence reductions [5]. Consequently, in 1978, iodization of all edible salt was made mandatory with an iodine standard set at $100 \mathrm{mg}$ iodine $/ \mathrm{kg}$ (equivalent to $168.5 \mathrm{mg}$ potassium iodate $/ \mathrm{kg}$ ). A micronutrient survey of 8-10 year-old school children in 1994 showed a significant reduction of goiter prevalence throughout Kenya, but residual goiter at $\geq 20 \%$ prevalence was still found in the historically most affected highland areas. During the next period of \pm 15 years, the strategy efforts became focused on methods and procedures for the improved performance of production and supply of iodized salt. After elevated iodine status findings were reported among schoolage children in the Midlands area, the Government of Kenya in 2009 lowered the mandatory iodine standard for salt to $30-50 \mathrm{mg}$ iodine $/ \mathrm{kg}$ salt, while maintaining potassium iodate as an exclusive fortificant $[6,7]$.

The iodization of salt for human consumption aims to raise the dietary iodine provision of a population through the salt used in preparation and seasoning of meals in the household, and through the salt used in the recipes of foods processed outside the home. The two additional iodized salt sources add dietary iodine on top of the native iodine (that is, iodine naturally present in foods and drinking water) [8]. In combination, the three dietary sources of iodine from household salt, processed food salt, and native iodine content are aimed at ensuring a total iodine intake from the diet that meets the biological needs of a population [9].

Setting an appropriate salt iodine standard depends on information about the native dietary iodine content and the consumption of salt from processed food and salt added in the household. In case these data are not available, international guidelines recommend a mean salt iodine standard content ranging between 20 and $40 \mathrm{mg}$ iodine per $\mathrm{kg}$, with the lower level of $20 \mathrm{mg} / \mathrm{kg}$ considered advisable when the salt used in processed food 


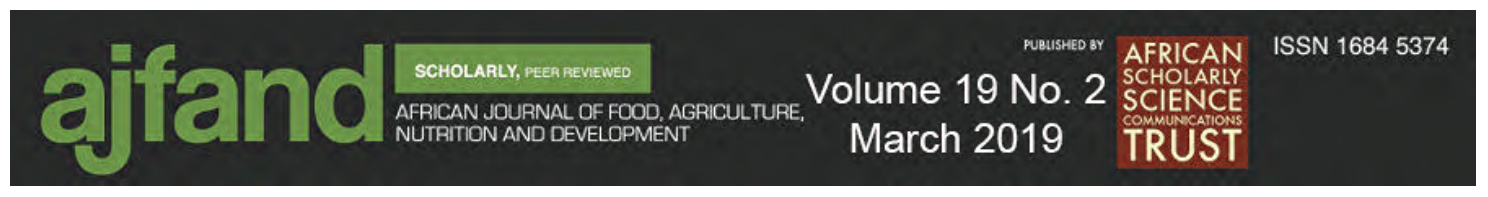

is also iodized [10]. For monitoring a population's iodine status and, if needed, adjusting the salt iodine standard, it is important to assess the fractions of total iodine intake that can be attributed to the native dietary iodine supply and the additional iodine supplies from salt in processed foods and from household salt. Ideally, such estimates would rest on dietary measurements of iodine and salt consumption.

Derived from the iodine content in soil and groundwater, naturally occurring dietary iodine varies considerably by geography [11], which makes an accurate estimate of native iodine consumption difficult. Seasonal variations in the iodine content of some foods and the limited available iodine data in food composition tables add to the difficulty of assessing the consumption of iodine by dietary methods $[12,13,14]$. In contrast, it is relatively simple to determine the typical iodine intake from iodine concentration data in casual urines of a large, representative population sample [13]. An accurate measurement of salt consumption is also not easy [14]. Dietary methods, such as duplicate diets, food frequency questionnaires and 24- hour dietary recalls, face limitations due to participant memory, and conversion with sodium values in food composition tables [15, 16]. Data of sodium content in food tables are often not up-to-date and, moreover, the amount of salt in the recipes of commercially manufactured foods can vary significantly by brand and even by company. Finally, the amount of sodium consumed from salt used in households, restaurants, and canteens cannot be measured accurately with the common existing dietary methods [17]. In contrast, sodium in excreted urine captures the discretionary salt consumption and does not depend on respondent recall or up-to-date detailed food composition data to calculate a sodium or salt intake estimate [18].

The Kenya National Micronutrient Survey 2011 (KNMS) was instigated by the Government of Kenya under the leadership of the Ministry of Health (formerly Ministry of Public Health and Sanitation) with the overall objective to obtain populationrepresentative data of nutrition and micronutrient status. Data collection from various population groups covered a range of micronutrients (including iodine), dietary intake and food product use patterns, child growth and development measurements, and information of infection patterns and common diseases. For comparison with previous findings in Kenya and in accordance with international guidelines school-age children (SAC) and non-pregnant, non-lactating women of reproductive age (NPW) were selected for collections of salt supply and use, and iodine status data [19]. A key underlying reason for the iodine component was to examine whether the new salt iodine standard was adequate to achieve a dietary iodine supply that provides optimal population iodine status. Because iodized food-grade salt is the principal means for delivering additional dietary iodine as well as the major dietary source of sodium, the KNMS protocol also included sodium concentration measurements in the same urine samples collected for iodine assessment [20].

Primarily, this report sets out to describe the findings of iodized salt supply and iodine status in SAC and NPW, based on the 2011 survey data. Second, the paper introduces an approach to apportion the principal sources of dietary iodine intake in the SAC and NPW of Kenya, taking advantage of the fact that both iodine and sodium concentrations were measured in the same casual urine samples. The objective of this paper, therefore, is to report the methods and findings of the iodine nutrition status of SAC and NPW, assessed 


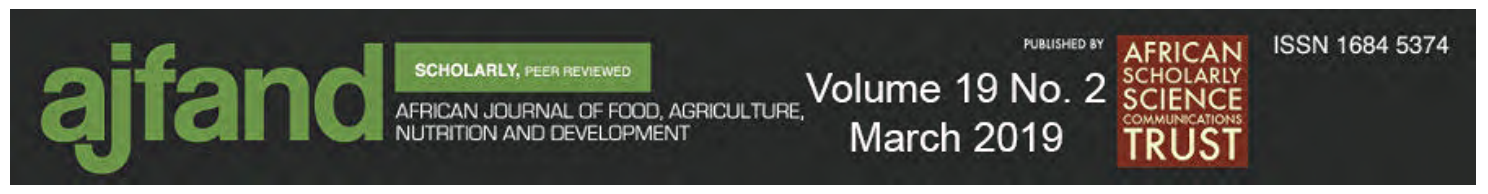

by their urinary iodine concentrations (UIC), and partitioned for each group into the three principal sources of iodine intake from the diet, namely, native iodine, processed food salt and household salt.

\section{MATERIALS AND METHODS}

\section{Selection of participants}

To obtain representative estimates nationally and separately for urban and rural areas, the design of the KNMS consisted of two-stage cluster sampling, stratified by urban and rural areas. The National Sample Survey and Evaluation Program IV master frame, maintained at the Kenya National Bureau of Statistics (KNBS), was used to systematically draw 296 clusters with equal probability from urban and rural areas. Urban areas were defined as cities, municipalities, town councils, urban councils, and all district headquarters, while the remaining areas of the country were classified as rural areas where people's main economic activity was farming. This first stage selection resulted in 123 urban and 173 rural clusters. At the second stage, 10 households were selected randomly from each cluster for general data collection. All eligible SAC (5-14y old) and NPW (aged 15-49y) residing in a random sub-sample of four out of the 10 selected households were invited for urine sampling and collection of salt supply and use data. The KNMS protocol was reviewed and approved by the Ethical Review Committee of the Kenya Medical Research Institutes (KEMRI) and written informed consent was obtained from all individuals who agreed to be enrolled. The survey participants did not receive a monetary incentive.

\section{Sample collection and processing}

The KNMS fieldwork took place from September to December 2011. Survey workers collected a single, $\pm 20 \mathrm{ml}$ "on-the-spot" urine sample from each SAC and NPW. Due to the nature of the survey, it was not possible to consistently collect the urine samples at a specified time of the day. At the same time also, a salt sample of $\pm 10 \mathrm{~g}$ was obtained from the household of each enrolled subject. One senior laboratory technician analyzed the urine samples in duplicate for urinary iodine concentration (UIC) and urinary sodium concentration (UNaC) in the Center for Public Health Research (CPHR) of KEMRI by a manual Sandell-Kolthoff method and atomic absorption spectrophotometry, respectively $[21,22]$. Salt samples were measured by one laboratory expert by single manual titration in the National Public Health Laboratory (NPHL) for potassium iodate content and converted to salt iodine (SI) content [23]. To keep analytical error within preset limits, the CPHR lab applied acceptance rules with UIC control limits set at values obtained from prior runs of left-over urine samples, and the NPHL lab used control limits for SI content similarly set from previous runs. From bench control pools, the total analytical error for UIC ranged between $5.2 \%$ and $7.9 \%$. The titration method achieved a total analytical variation of $5.0 \%$. The accuracy of UIC and SI data was assessed in a blinded three-way inter-laboratory comparison with two separate accredited iodine laboratories in Tanzania and Kazakhstan. Comparisons of reported data showed no significant difference in UIC results between laboratories, but the SI data reported by the NPHL were consistently higher by $6.9 \mathrm{mg} / \mathrm{kg}$ compared with the mean SI results of the two external laboratories [24]. For the regression analyses reported in this paper, the SI data of the NPHL was therefore reduced by $6.9 \mathrm{mg} / \mathrm{kg}$ to ensure internal consistency of the 


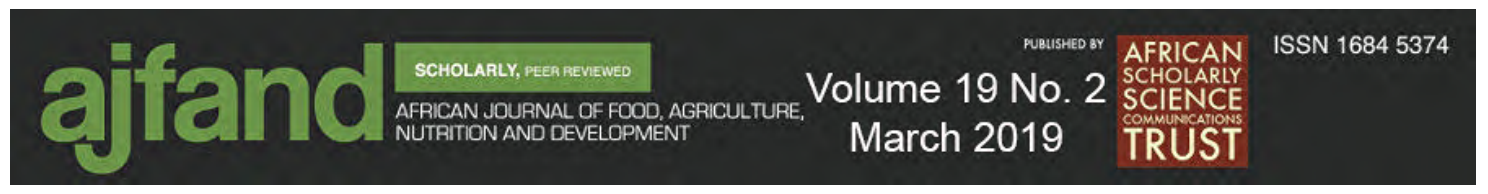

dietary iodine source estimations. During the period of KNMS urine sample processing, the CPHR laboratory earned a certificate of successful performance from the Ensuring the Quality of Urinary Iodine Procedures program at the Centers of Disease Control and Prevention, Atlanta, USA [25].

\section{Statistical Analysis}

Descriptive findings for UIC, UNaC and SI were obtained with SPSS on weighted data to account for refusal, absence from the household and missing data. For UIC, findings were reported as median values and interquartile ranges (IQR). For UNaC, means and $95 \%$ confidence intervals (95\% CI) and for SI, means and standard deviations (SD) were reported. Findings were categorized by age, gender, residence type, region and household wealth index, as applicable. Pearson's $\chi^{2}$ test was used to test associations between UIC levels and co-factors and Fisher's $\mathrm{F}$ ratio was used for testing associations of co-factors with $\mathrm{UNaC}$ levels.

Combined data processing of the UIC, $\mathrm{UNaC}$ and SI data was conducted by generalized linear regression (GLR) as described by Heeringa et al. [26], after transformation of the UIC data to their natural logarithms. The regression technique aimed to examine those variables that were making important contributions in explaining the variation of UIC values in each survey group. In the data processing with GLR, the UIC data (a biomarker of iodine intake) of SAC and NPW were positioned as the outcome variable and the $\mathrm{UNaC}$ (salt use indicator) and SI (iodine quality of household salt) data as explanatory variables. Residence type (a dichotomous variable) of the household was also added as an explanatory factor to assess the influence of a household's location on the UIC while taking the $\mathrm{UNaC}$ and SI effects into account. Weighted regression analyses of the $\log \mathrm{UIC}$ data were performed in Stata 14 and R software (StataCorp LP, College Station, Texas) with settings for the two-stage stratified cluster survey design. The aptness of models was assessed graphically, homoscedasticity was examined by plotting of the standardized residuals against predicted $\log$ UIC values and the normality of residuals was checked by probability plots. Calculation of $95 \%$ confidence intervals did not include a finite population correction as the population size of Kenya is large compared to the sample sizes of SAC and NPW.

Mean estimates for UIC portions that correspond with the three sources of iodine intake (native dietary content, processed food salt, and household salt) were derived with the intercept and slope estimates obtained from GLR analyses as follows. First, the logUIC intercept estimate was back-transformed to its corresponding UIC value, which is the geometric mean UIC value that does not depend on either the UNaC or the SI value when both are zero. The resulting finding is interpreted as the UIC part that corresponds with the native dietary iodine content. Second, the back-transformed UIC value was calculated with the intercept and slope while inputting the respective group's average UNaC value and keeping the SI value at zero. The resulting finding corresponds to the mean UIC of the group due to the mean dietary sodium content without iodine contained in household salt. The difference between this UIC finding and the former UIC value derived from the intercept alone is interpreted as the UIC part that corresponds with dietary iodine intake from salt contained in processed food. Finally, the difference between the group's total UIC finding and the UIC estimate arising from sodium content in the diet, that is, the 


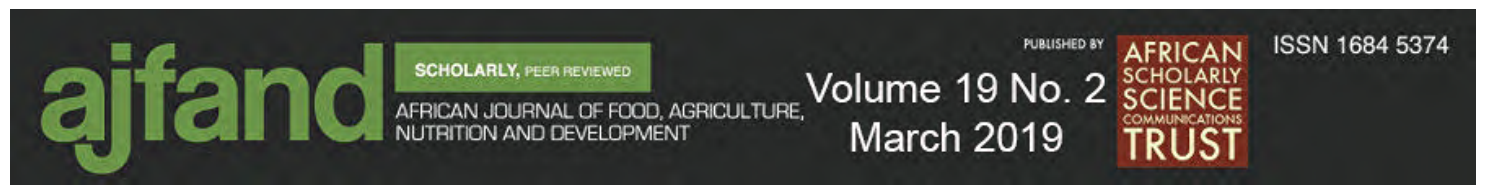

result obtained in step two, was interpreted as the UIC part that corresponds with the iodine intake obtained from household salt.

\section{RESULTS AND DISCUSSION}

\section{Participant Response rates}

For iodine status assessment, the KNMS set out to enroll all the SAC and NPW in 740 households (the number of households includes $10 \%$ refusal). Based on the master frame, 1,072 SAC and 1,708 NPW were projected to reside in the 740 targeted households. SI data were obtained from 625 households (84.5\% response rate); UIC was measured in 951 urine samples of SAC (88.7\% response) and 623 urine samples of NPW $(36.5 \%$ response), and $\mathrm{UNaC}$ data were obtained from $863 \mathrm{SAC}$ (80.5\% response) and $579 \mathrm{NPW}$ (33.9\% response). Complete sets of indicator variables for multiple GLR analysis were available from 563 SAC (53\% of expected) and 382 NPW (22\%).

\section{Iodized salt supply}

The minimum SI content in the 625 household samples collected in this survey was 1.6 $\mathrm{mg} / \mathrm{kg}$ and the maximum $150.2 \mathrm{mg} / \mathrm{kg}$. The mean SI content of all salt samples (Table 1) was $40.3 \mathrm{mg} / \mathrm{kg}$ (SD $19.4 \mathrm{mg} / \mathrm{kg}$ ). The SI contents in $94.9 \%$ of salt samples were $\geq 15$ $\mathrm{mg} / \mathrm{kg}$ and in $70.1 \%$ of households, the SI values ranged between 20 and $50 \mathrm{mg} / \mathrm{kg}$. Variations in SI content across regions were significant $(P=0.018)$, with Coast region (mean $\pm \mathrm{SD}: 46.7 \pm 24.1 \mathrm{mg} / \mathrm{kg}$ ) having highest and Eastern region $(36.0 \pm 15.7 \mathrm{mg} / \mathrm{kg}$ ) having lowest SI levels. Urban households had higher SI contents in their salt $(41.9 \pm$ $20.3 \mathrm{mg} / \mathrm{kg})$ than rural households $(39.0 \pm 18.5 \mathrm{mg} / \mathrm{kg})$, but this difference did not attain statistical significance $(P=0.063)$. Also, while the SI content in Kenya's leading salt brand $(39.8 \pm 19.3 \mathrm{mg} / \mathrm{kg})$ was lower than in all other brands combined $(41.4 \pm 19.5$ $\mathrm{mg} / \mathrm{kg})$, the difference was not statistically significant $(P=0.350)$.

The KNMS findings of household SI content demonstrate high dedication by the salt industries in meeting mandated standards in iodizing edible salt at 30-50 mg iodine $/ \mathrm{kg}$. The mean household SI content of $40.3 \mathrm{mg} / \mathrm{kg}$, a small proportion of SI values below 15 $\mathrm{mg} / \mathrm{kg}$ and the substantial majority of SI findings in the range preferred at the level of households shows that the USI strategy in Kenya performed successfully [13]. Nevertheless, the fraction of iodized salt sold for direct household use represents only a partial picture of the total edible salt supply. Salt for use in food manufacturing, such as in food processing industries, restaurants, catering, food aid, and street-side food vending constitutes a separate, meaningful source of salt intake for many people [9]. Therefore, to ascertain that the USI strategy is really loyally executed, it is important to also have information about the iodine intake from the use of iodized salt in these forms of processed foods.

\section{Population iodine status}

Urinary Iodine Concentration (UIC) findings in SAC and NPW are reported in Table 2 and Table 3, respectively. The median UIC in SAC was $208 \mu \mathrm{g} / \mathrm{L}$ (IQR: 108 - 333) and in NPW 167 $\mu \mathrm{g} / \mathrm{L}$ (IQR: 98 - 299), that is, both within the range considered 


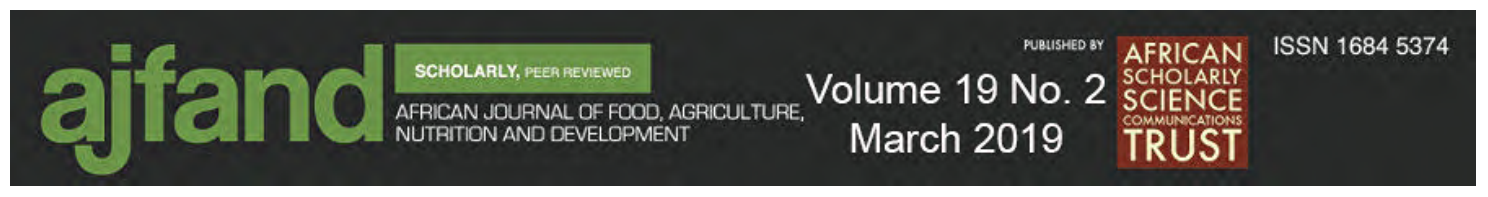

internationally as indicative of adequate iodine nutrition. The median UIC in male SAC (231, IQR: $119-368 \mu \mathrm{g} / \mathrm{L})$ was higher $(P=0.002)$ than in females (190, IQR 99 - 295 $\mu \mathrm{g} / \mathrm{L})$. Higher median UIC values were also found in urban, compared to rural households, both in SAC (231, IQR 153 - $341 \mu \mathrm{g} / \mathrm{L} v s .188$, IQR $99-327 \mu \mathrm{g} / \mathrm{L}$, respectively, $P<0.001)$ and NPW (180, IQR $125-321 \mu \mathrm{g} / \mathrm{L} v s .163$, IQR $90-279 \mu \mathrm{g} / \mathrm{L}$, $P=0.008)$. Median UIC levels in SAC as well as NPW varied across regions and household wealth categories (all $P<0.001$ ). Thus, highest median UIC in SAC and NPW were from North Eastern region, followed by Nairobi, Central, Coast and Eastern regions and lowest UIC levels were found in Nyanza, Rift Valley, and Western regions. Classified by household wealth levels, the SAC and NPW in the wealthiest households had highest median UIC, while UIC levels in SAC and NPW from poorer homes were lowest.

A key purpose of the UIC measurements was to assess the iodine status in the population of Kenya after the sizeable downward revision of the national salt iodine standard in 2009. Both the median UIC findings in SAC (median 208; IQR $108-333 \mu \mathrm{g} / \mathrm{L}$ ) and NPW (median 167; IQR $98-299 \mu \mathrm{g} / \mathrm{L}$ ) were within the range of optimal iodine nutrition and, despite the clear variations of UIC levels by various categories, virtually all median UIC findings fell within the adequacy range of 100-300 $\mu \mathrm{g} / \mathrm{L}$, with a single exception of North-Eastern region, where the median UIC levels, particularly in SAC, were starkly elevated $[13,27]$. High iodine concentrations have been reported previously in drinking water samples taken from spring, well and river sources along the Rift Valley of Ethiopia and a more recent national iodine survey in Somalia similarly found high iodine content in drinking water from boreholes [[28, 29]. Hence, the elevated UIC levels in Kenya's North-Eastern region, which borders on Ethiopia and Somalia, may be related to high iodine content in drinking water and were likely not caused by excessive salt intake or high SI content in salt. A revision of the salt iodine standard would have little effect in such a case. It is also worth noting that the median UIC levels in the historically most affected highland areas of Nyanza and Rift Valley regions were only slightly above the minimum threshold for iodine deficiency. Therefore, reducing the current salt iodine standard would conceivably put the population in the historically most affected areas at risk of recurrent iodine deficiency.

\section{Urinary sodium concentrations}

The UNaC findings for the SAC and NPW groups are presented in Table 4 and Table 5, respectively. The mean UNaC in SAC was $192 \mathrm{mmol} / \mathrm{L}(95 \% \mathrm{CI}: 185,199)$ and in NPW $186 \mathrm{mmol} / \mathrm{L}(95 \% \mathrm{CI}: 178,193)$. Male SAC had higher mean $\mathrm{UNaC}(P<0.001)$ values than females. Higher UNaC levels were also found for both groups in urban, compared to rural households $(P<0.001)$. As was the case for the UIC findings, UNaC levels in both SAC and NPW were strongly associated with the region and household wealth category (all $P<0.001$ ). In each survey group, the $\mathrm{UNaC}$ findings were higher in Nairobi, Coast, and Eastern regions, while they were lower in Nyanza, Rift Valley and Western regions. SAC and NPW who lived in the wealthiest households had the highest mean $\mathrm{UNaC}$ findings, while lowest $\mathrm{UNaC}$ values were found in the poorer households.

As is the case for iodine, sodium consumed with the diet also ends up in urine, but unlike iodine, the amount of excreted sodium is regulated by hormonal actions on the kidneys 


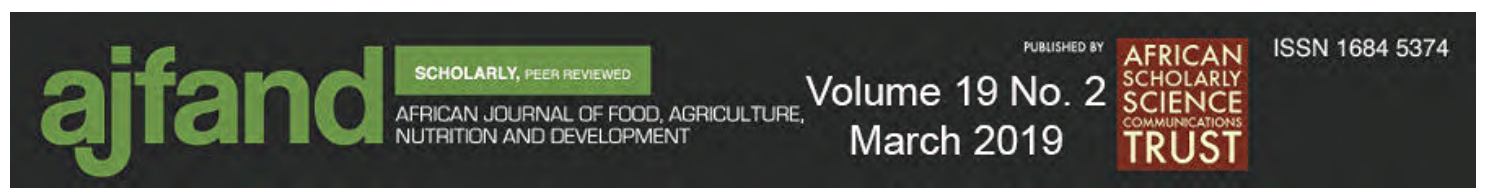

for maintenance of water and sodium homeostasis [18]. Population salt intake estimates derived from casual urine sample collections are therefore deemed less robust than 24-h urine sampling and a recent taxonomy by the World Hypertension League (WHL) for classifying population salt intakes does not include criteria for spot $\mathrm{UNaC}[[30,31]$. In the absence of any other authoritative guidance, this report nonetheless used the WHL cut-off values to describe the $\mathrm{UNaC}$ distributions and for comparing the $\mathrm{UNaC}$ levels by different categories.

The existing difference between physiological control of the excretions of iodine and sodium in urine would suggest that the iodine and sodium amount in casual urine samples of individuals do not necessarily vary in tandem, even when the habitual consumption of iodine and sodium with the diet are both largely supplied with iodized salt. However, because the volume of urine and, therefore, the concentrations of iodine and sodium in urine also depend on the amount of water intake the kidney's control of the amount of urine volume gives reason to expect that the UIC and UNaC values in the groups of SAC and NPW may be co-varying. This is consistent with global experience [31, 32-34] that the urinary excretions of iodine and sodium are closely related to the consumption of iodized salt in countries, such as Kenya, with a well-established USI strategy. That covariation of UIC and UNaC values indeed existed in the KNMS survey groups was evident from the very similar fluctuation patterns of UIC and UNaC findings, classified by residence, region and household wealth index, as illustrated in Figure 1. Both urinary indicators were higher in urban areas, Coast region, and the wealthiest households, while they were lowest in rural households, Rift Valley and Western regions, and in poorer households. 

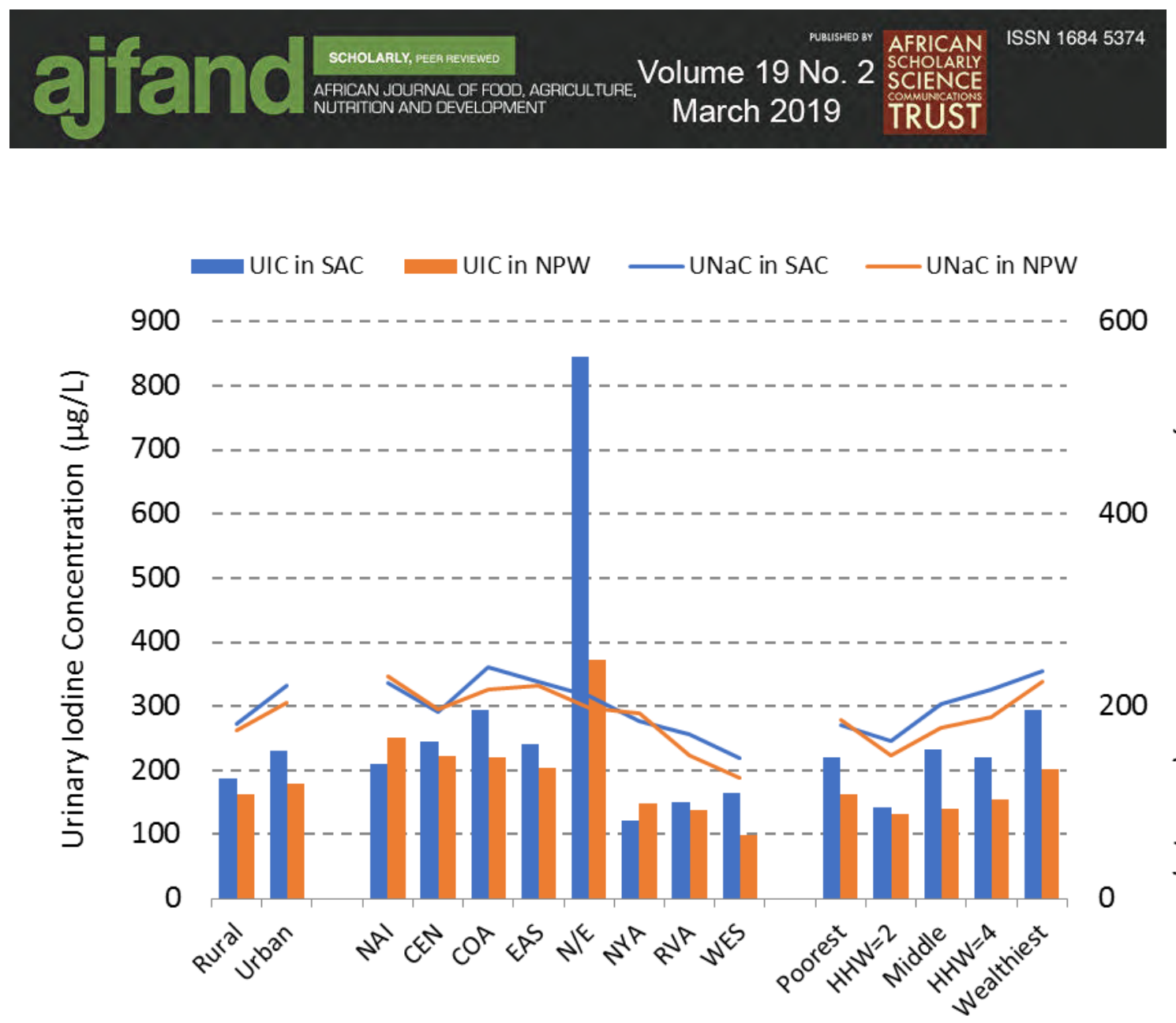

Note: $\mathrm{NAI}=$ Nairobi, $\mathrm{CEN}=$ Central, $\mathrm{COA}=$ Coast, $\mathrm{EAS}=$ Eastern, $\mathrm{N} / \mathrm{E}=$ North-Eastern, NYA $=$ Nyanza, $\mathrm{RVA}=$ Rift Valley and WES $=$ Western region

\section{Figure 1: Median UIC (left-hand scale) and mean UNaC (right-hand scale) findings in SAC and NPW by household location, region and household wealth index, Kenya 2011}

Figure 1 illustrates that the high UIC values of SAC and NPW in North-Eastern region diverged from the pattern of close covariation of group-wise UIC and UNaC findings. As suggested before, a likely high iodine content of drinking water in the North-Eastern region may have been the reason for this discrepancy. These strong overall associations between the UIC and the $\mathrm{UNaC}$ levels indicate that the variations in UIC levels of both survey groups were largely explained by the variations of their $\mathrm{UNaC}$ data. This supports the idea that the amount of (iodized) salt consumption is a key determinant of the iodine intake and, thus, iodine status of the population of Kenya.

\section{Partitioning of dietary iodine sources}

The first GLR model aimed to examine the dependency of the UIC outcome variable within each group on the explanatory variables UNaC, SI and household residence [26]. Results reported in Table 6 show that in each group, the UIC showed highly significant associations with variations of UNaC $(P<0.001)$ and household SI content, which attained statistical significance in NPW $(P<0.05)$. The rural residence did not contribute significantly in explaining UIC levels within each group when the $\mathrm{UNaC}$ and SI variables were considered. 


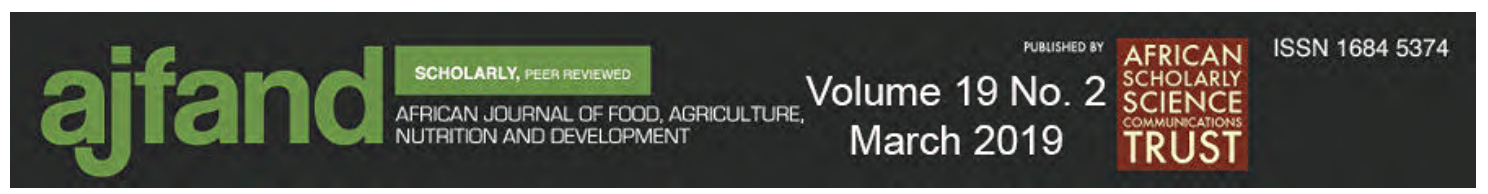

Next, the regression estimates reported in Table 6 were used to calculate the UIC portions that correspond with the key sources of dietary iodine (Table 7). The UIC fractions due to native iodine in the diet were below the $100 \mu \mathrm{g} / \mathrm{L}$ threshold for iodine deficiency $(60.5$ $\mu \mathrm{g} / \mathrm{L}$ and $66.8 \mu \mathrm{g} / \mathrm{L}$ in SAC and NPW, respectively). The UIC fractions corresponding with iodine in processed food were larger $(86.7 \mu \mathrm{g} / \mathrm{L}$ in SAC and $83.7 \mu \mathrm{g} / \mathrm{L}$ in NPW), while the UIC levels attributable to iodine from household salt were smaller $(47.0 \mu \mathrm{g} / \mathrm{L}$ and $29.8 \mu \mathrm{g} / \mathrm{L}$ in SAC and NPW, respectively). These findings for apportioned UIC levels suggest that in SAC, $31 \%$ of the total iodine intake was sourced from the native iodine content, and $45 \%$ and $24 \%$, respectively, from iodized salt in processed foods and from iodized household salt. The respective UIC portion estimates in NPW were: native dietary iodine $37 \%$, food salt iodine $47 \%$ and household salt iodine $17 \%$.

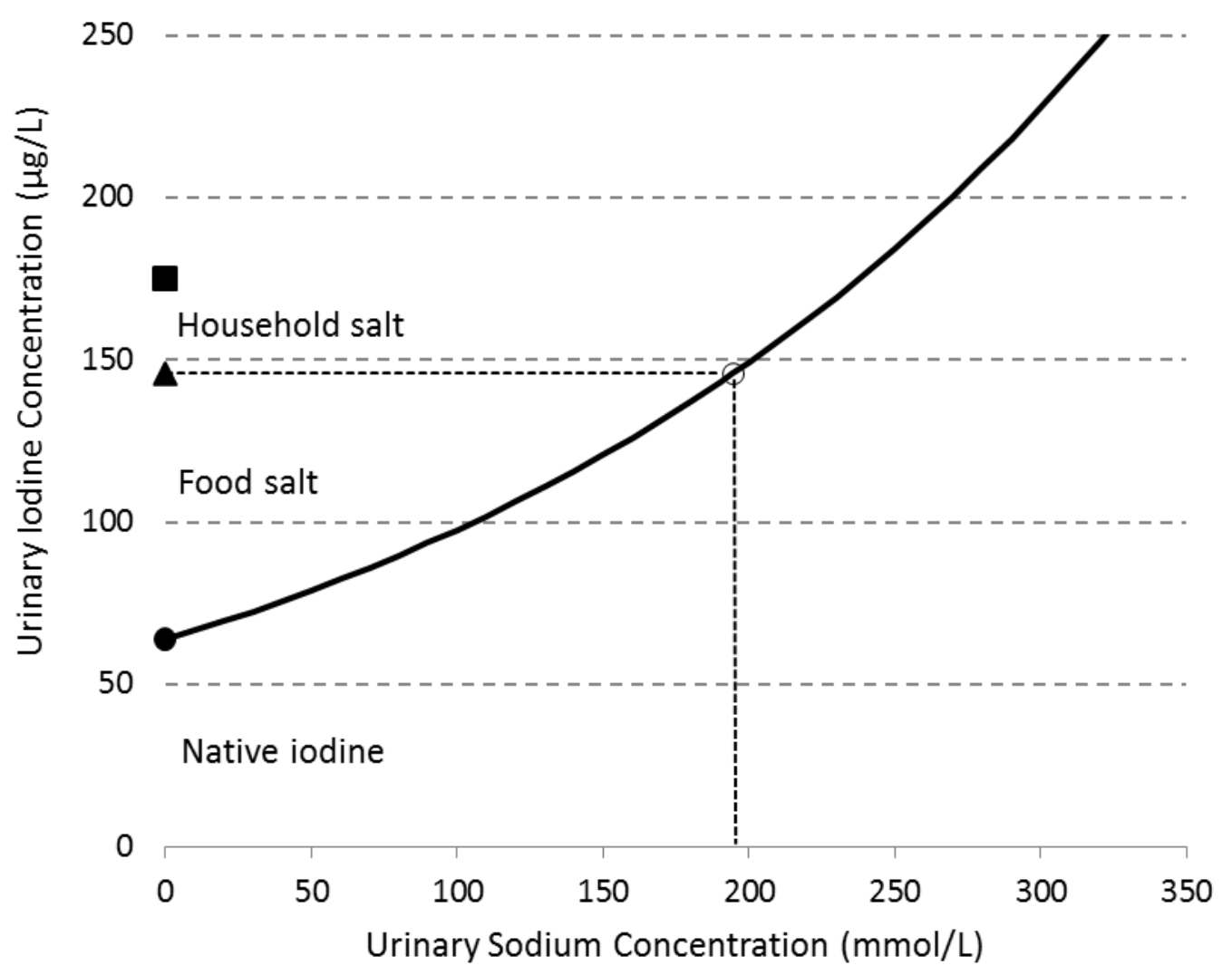

Note: UIC levels are calculated with use of the GLR parameter estimates reported in Table 6. Marker symbols on the ordinate show UIC portions that correspond with native dietary iodine (circle), native dietary plus food salt iodine (triangle) and total dietary iodine (square)

\section{Figure 2: Calculation of UIC estimates corresponding with the key sources of dietary iodine in urban non-pregnant women, Kenya 2011}

To our knowledge, the use of regression to apportion the UIC findings from a population survey has not been described previously. Because the findings reported in Table 6 may not be familiar, Figure 2 illustrates an example of the calculation of UIC portions in urban NPW. The rising line in Figure 2 portrays the main association between the UIC and 


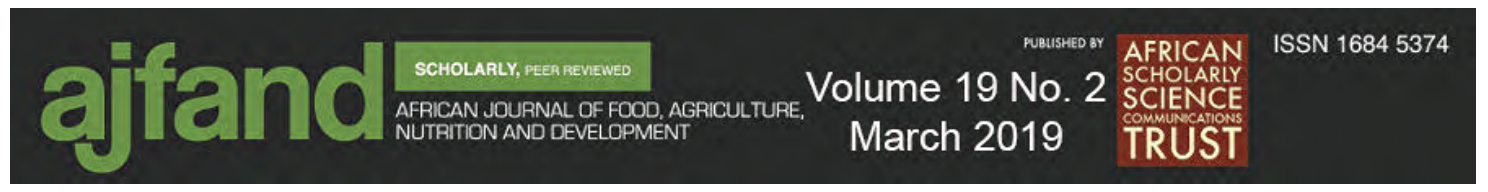

$\mathrm{UNaC}$ values in urban NPW, adjusted for SI content and residence. Marker symbols on the ordinate (Y-axis) indicate UIC portions obtained from back-transformed logUIC findings, that is, UIC $=e^{z}$, in which the $z$ values are calculated in three steps with the GLR parameters reported in Table 6 . In sequence, these steps proceed as follows:

(1) The start-out $z$ value equals the intercept estimate for NPW, that is, $z=4.158$. Then, the back-transformed UIC value is $e^{4.158}=63.9 \mu \mathrm{g} / \mathrm{L}$ (indicated by the round symbol on the ordinate). This finding is interpreted as the UIC part in urban NPW that corresponds with native dietary iodine intake

(2) In the $2^{\text {nd }}$ step, $z$ is calculated with the regression equation using the average $\mathrm{UNaC}$ finding in urban NPW (mean $\mathrm{UNaC}=194.6 \mathrm{mmol} / \mathrm{L}$ ). Then, $z=4.158$ $+0.0042 \times 194.6=4.982$ and $e^{4.982}=145.8 \mu \mathrm{g} / \mathrm{L}$ (the triangular symbol). The UIC fraction in urban NPW from iodine intake in processed foods is obtained as the increment above the step (1) result, that is, $\mathrm{UIC}=145.8-63.9=81.9$ $\mu \mathrm{g} / \mathrm{L}$

(3) The $3^{\text {rd }}$ step uses the total geometric mean UIC in urban NPW (square symbol $=174.9 \mu \mathrm{g} / \mathrm{L}$ ) and obtains the increment above the result of step (2): UIC = $174.9-145.8=29.1 \mu \mathrm{g} / \mathrm{L}$. This finding is interpreted as the UIC part in urban NPW that corresponds with iodine intake from household salt.

Two findings from the technique to apportion the UIC values to the dietary sources of iodine intake (Table 7) should be noted. First, in both survey groups, the estimated UIC parts attributed to native dietary iodine content fell below the $100 \mu \mathrm{g} / \mathrm{L}$ threshold for iodine deficiency. This implies that iodine deficiency can be expected to reoccur in the population should the USI strategy in Kenya be suspended. Second, the finding of very similar GLR parameter estimates for the $\mathrm{UNaC}$ variable (Table 6) suggests that in both groups (SAC and NPW) the UIC levels are impacted in the same way by the salt consumed from their diets. The different findings for total UIC between SAC and NPW would, therefore, mainly be caused by a difference in dietary consumption between children and adults, and less so by a different composition of their diets.

It is noteworthy also, that the estimates of UIC portions are imprecise. A first reason for the wide CIs around the UIC point estimates is that the numbers of SAC and NPW with a complete dataset was small, which made for relatively high imprecision of UIC portion findings in each group. The second reason for imprecision is inherent in the technique of generalized regression [26]. To account for the uncertainty related to finite sample selection in the survey, the statistical analysis applied design-based (generalized) linear regression, which is superior to simple regression because it yields more accurate regression parameter estimates. However, the higher accuracy of the GLR technique comes at the cost of less certainty and, consequently, wider CIs for the UIC part estimates. Figure 3 shows findings of the UIC parts corresponding with the key dietary iodine sources in each survey group and illustrates their wide CIs. 

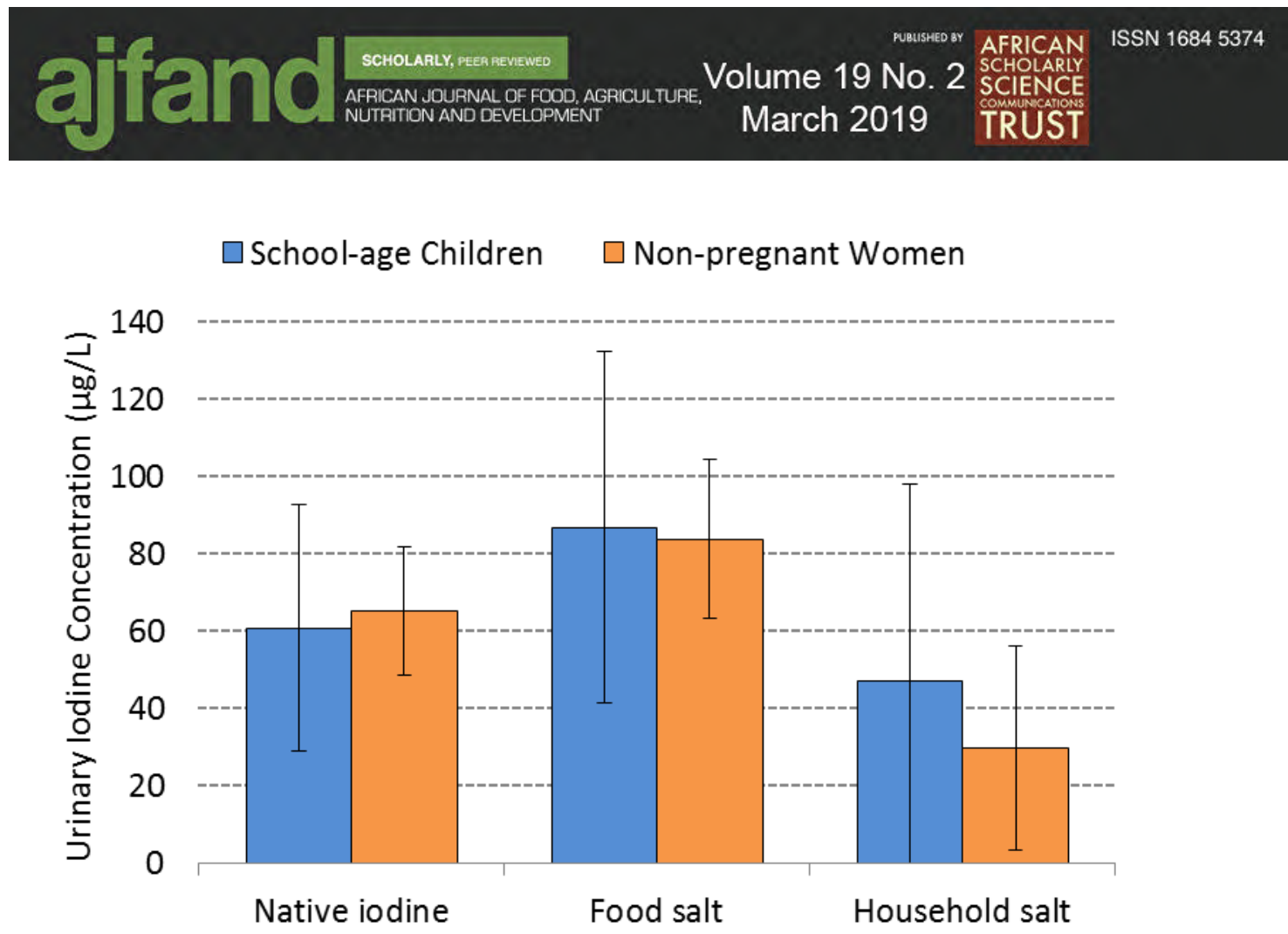

Figure 3: Estimated UIC levels and $95 \%$ confidence intervals corresponding with the key sources of iodine intake in school-age children and non-pregnant women, Kenya 2011

Finally, an extended GLR model to analyze differences between survey groups (Table 8) found that the adjusted effects from variations in the UNaC and the SI values on the UIC did not differ significantly ( $P=0.82$ for $\mathrm{UNaC}$ and $P=0.56$ for SI) between the groups of SAC and NPW. Also, no significant difference was found for the different effect between survey groups on the UIC when adjusted for all the other explanatory variables of interest $(P=0.68)$. The lack of significance for the difference between survey groups and for the different $\mathrm{UNaC}$ and $\mathrm{SI}$ associations within survey groups buttresses the previous inference that the UIC levels in SAC, as well as NPW, are primarily and in a similar way explained by their UNaC and SI values, and that the different median UIC findings for the SAC and NPW groups are likely, not due to a difference in composition of the diet between the children and adults.

Among the limitations of the present study is that the native dietary sodium content was not considered when deriving the UNaC-related UIC portions. Studies of typical diets in the UK and the US, and a recent analysis of iodine intakes in Swiss adults reported that $12-18 \%$ of the dietary sodium in these industrialized countries comes from the sodium "naturally" contained in foods[35, 36, 37]. An estimate for native-source dietary sodium in less industrialized countries could not be found. The native dietary sodium content might be somewhat lower in Kenya where cereals, beans, and horticultural products are important items in the common food basket [37]. Nevertheless, an approach that estimates the UIC parts with the UNaC set at the level of native-source sodium would have allowed more accurate estimates of the native dietary and processed food sources of iodine intake. 


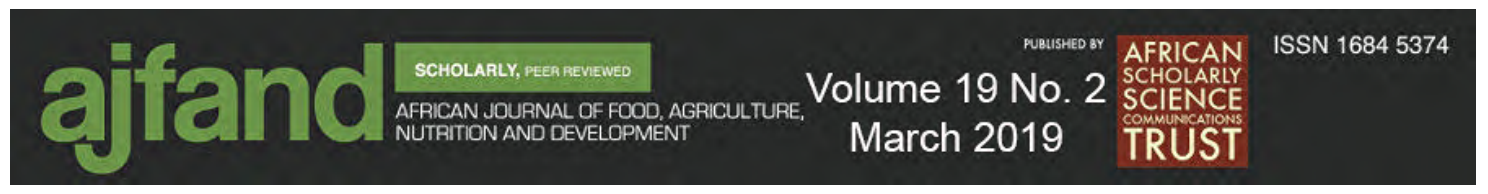

The strength of this study would be the illustration of a practical approach to approximate the sources of dietary iodine in a population from data of a national house-to-house survey, without placing an additional burden on the respondents. The approach adds only a small expense for sodium analysis in the urine samples that are already collected for iodine assessments. Practical advantages in large surveys of spot urine sampling over 24 hour collections have been described and there is also growing recognition that the mean $\mathrm{UNaC}$ from a large number of spot urine samples can approximate the mean daily sodium excretion well enough for the purposes of comparing and tracking population sodium intake over time $[[38,39,40]$. Similarly, the current UIC partitioning approach by way of the $\mathrm{UNaC}$ levels in spot urine may approximate the proportions of iodine intake sources well enough to be of use for monitoring future changes in iodine intakes from processed food salt and household salt.

For improving the iodine intake apportioning technique, priority would be to correct the $\mathrm{UIC}$ and $\mathrm{UNaC}$ data for their typical within-person variation $[30,31]$. As suggested for spot UNaC data of US adults [41] and shown for spot UIC data of SAC a repeat collection of urine samples from a subset of survey participants can be used to adjust the UIC and $\mathrm{UNaC}$ data to more closely resemble their habitual distributions[42]. Use of adjusted $\mathrm{UNaC}$ data for UIC partitioning would increase the accuracy of the UNaC regression coefficient and thereby yield more accurate point estimates for the native dietary and processed food source iodine intakes. And the use of adjusted UIC data would reduce the uncertainties of all three UIC portion estimates [43].

In view of an anticipated increase in hypertension prevalence worldwide, the World Health Organization (WHO) is promoting initiatives in each country toward a reduction of $30 \%$ in mean population salt consumption by 2025 [44]. On preciously little and dated information, the Global Burden of Diseases study in 2010 classified Kenya's sodium intake among the East Sub-Sahara African countries with the lowest salt intakes of all regions in the world $[45,46]$. The purpose in the KNMS of including UNaC data collection was not to obtain equivalent salt intake estimates but to assist in a more refined analysis of the iodine status assessment. Nevertheless, as noted in a recent review of the use of $\mathrm{UNaC}$ from casual (spot) urine sampling, several countries have elected casual urine sampling for population surveillance and tracking of change in salt intakes [47]. There is increased acceptance that spot urine measurements may be sufficiently robust and be the preferred method in large population surveys [39, 40]. Hence, the current mean UNaC findings in SAC and NPW could be a useful reference point for future efforts to reduce population salt intake in Kenya.

\section{CONCLUSION}

Over the past decades, major progress has been made in Kenya towards the national objective of ensuring optimal iodine nutrition of the population. The Government of Kenya has enacted regulations that compel universal supplies of adequately iodized salt for household use. Kenya's salt industries have stepped up the assurance of adequately iodized salt deliveries, while the Kenya Bureau of Standards is keeping close oversight of iodization performance in salt factories, with support from partner Ministries. The 


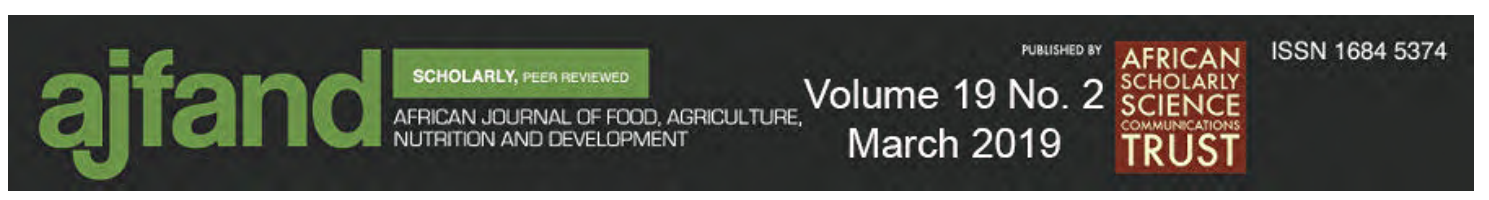

benefits of this collaboration are clear from the KNMS findings of high-quality iodized salt supply, adequate iodine intake and optimal population iodine status in Kenya. These findings do not suggest a need to change the salt iodization strategy or to adjust the current salt iodine standard. The major remaining challenge in Kenya, then, is to make sure that the success of preventing iodine deficiency disorders with the current USI strategy will be sustained.

\section{Acknowledgements}

Technical support in data processing was provided by the Statistical Service Center, University of Reading, UK (Alessandro Leidi, Cathy Garlick). We are grateful for assistance from Laird Ruth of the Centers for Disease Control and Prevention, Atlanta, GA, USA in adding the urinary sodium measurements to the survey protocol

\section{Funding sources}

Nutrition International (formerly Micronutrient Initiative), Iodine Global Network, Bill and Melinda Gates Foundation

\section{Authors' contributions}

$\mathrm{ZB}, \mathrm{FH}, \mathrm{LM}$ and $\mathrm{JN}$ designed the iodine survey component; ZB, MM, GM, JM, LK, PN and YK conducted field research; PN performed laboratory analyses; $\mathrm{MM}$ and $\mathrm{FH}$ conducted statistical analyses; $\mathrm{ZB}, \mathrm{FH}$ and $\mathrm{MM}$ wrote the manuscript with inputs from all the co-authors; ZB had final responsibility for content. All authors read and approved the final manuscript

\section{Conflict of interest statement}

The authors declare no conflict of interest 


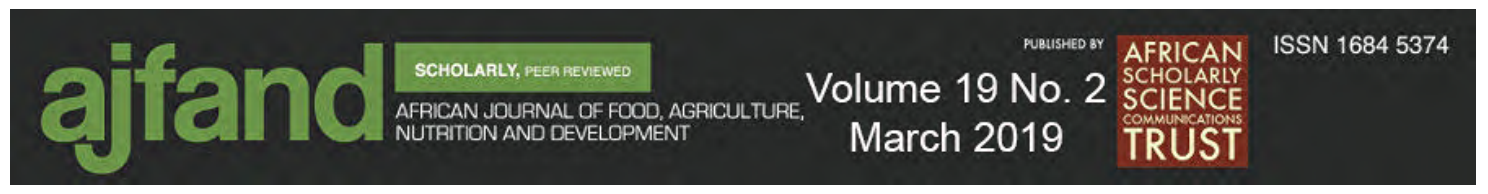

Table 1: Iodine content (mg/kg) in household salt, Kenya 2011

\begin{tabular}{|lcccr|}
\hline & $\begin{array}{c}\text { Number of } \\
\text { samples }\end{array}$ & Mean & SD & \multicolumn{1}{c|}{$\begin{array}{r}\text { Fisher's F } \\
P \text {-value }\end{array}$} \\
\cline { 1 - 1 } Residence & & & & 3.47 \\
\cline { 1 - 1 } Rural & 343 & 39.0 & 18.5 & 0.063 \\
\cline { 1 - 1 } Region & 280 & 41.9 & 20.3 & 5.63 \\
\cline { 1 - 1 } Nairobi & 58 & 38.0 & 19.6 & 0.018 \\
Central & 74 & 41.9 & 23.9 & \\
Coastal & 63 & 46.7 & 24.1 & \\
Eastern & 94 & 36.0 & 15.7 & \\
N/Eastern & 23 & 38.4 & 14.1 & \\
Nyanza & 104 & 40.8 & 19.2 & \\
Rift Valley & 137 & 41.0 & 15.2 & \\
Western & 71 & 37.8 & 17.6 & \\
\hdashline Kenya & 625 & 40.3 & 19.4 & \\
\hline
\end{tabular}




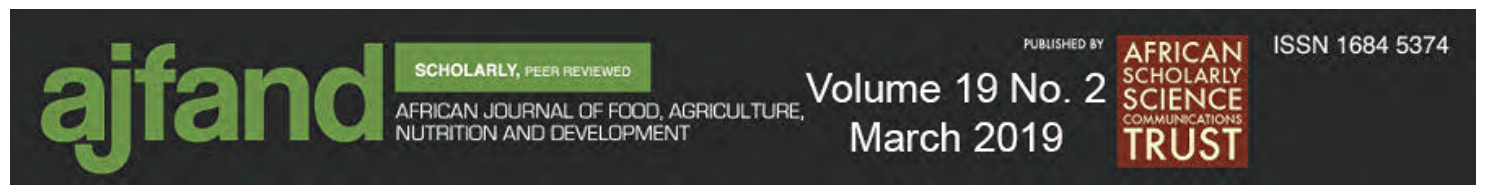

Table 2: Urinary Iodine Concentration $(\mu \mathrm{g} / \mathrm{L})$ in School-Age Children, Kenya 2011

\begin{tabular}{|c|c|c|c|c|c|c|c|c|c|}
\hline \multirow[b]{2}{*}{ Category } & \multirow[b]{2}{*}{$\mathrm{n}$} & \multirow[b]{2}{*}{ Median } & \multirow{2}{*}{\multicolumn{2}{|c|}{ IQR }} & \multicolumn{4}{|c|}{ UIC distribution shares $(\%)$} & \multirow{2}{*}{$\begin{array}{l}\chi^{2} \text { and } \\
P \text {-value }\end{array}$} \\
\hline & & & & & $<100$ & $100-299$ & $300-499$ & $\geq 500$ & \\
\hline Age & & & & & & & & & 5.99 \\
\hline 5 to $8 y$ & 433 & 200 & 109 & to 310 & 21 & 51 & 18 & 10 & 0.112 \\
\hline 9 to $14 \mathrm{y}$ & 518 & 217 & 107 & to 349 & 23 & 45 & 17 & 15 & \\
\hline Gender & & & & & & & & & 14.85 \\
\hline Male & 478 & 231 & 119 & to 368 & 19 & 45 & 21 & 15 & 0.002 \\
\hline Female & 473 & 190 & 99 & to 295 & 25 & 50 & 14 & 11 & \\
\hline Residence & & & & & & & & & 24.15 \\
\hline Rural & 699 & 188 & 99 & to 327 & 25 & 46 & 15 & 14 & $<0.001$ \\
\hline Urban & 252 & 231 & 153 & to 341 & 14 & 51 & 25 & 10 & \\
\hline Region & & & & & & & & & 344.8 \\
\hline Nairobi & 49 & 209 & 169 & to 313 & 6 & 55 & 38 & 2 & $<0.001$ \\
\hline Central & 97 & 244 & 130 & to 348 & 18 & 40 & 28 & 13 & \\
\hline Coast & 78 & 294 & 170 & to 481 & 8 & 46 & 23 & 23 & \\
\hline Eastern & 139 & 240 & 178 & to 457 & 9 & 50 & 19 & 22 & \\
\hline N/Eastern & 77 & 846 & 303 & to 1157 & 3 & 19 & 13 & 65 & \\
\hline Nyanza & 138 & 122 & 88 & to 222 & 30 & 61 & 8 & 1 & \\
\hline Rift Valley & 258 & 151 & 81 & to 275 & 36 & 46 & 16 & 2 & \\
\hline Western & 115 & 164 & 72 & to 245 & 32 & 53 & 12 & 3 & \\
\hline HH wealth & & & & & & & & & 80.9 \\
\hline Poorest & 241 & 221 & 106 & to 349 & 23 & 46 & 14 & 16 & $<0.001$ \\
\hline $\mathrm{HHW}=2$ & 270 & 142 & 83 & to 243 & 32 & 48 & 14 & 6 & \\
\hline Middle & 206 & 233 & 72 & to 393 & 20 & 45 & 14 & 21 & \\
\hline $\mathrm{HHW}=4$ & 135 & 220 & 155 & to 346 & 11 & 61 & 22 & 7 & \\
\hline Wealthiest & 99 & 294 & 192 & to 405 & 11 & 40 & 33 & 16 & \\
\hline All SAC & 951 & 208 & 108 & to 333 & 22 & 47 & 18 & 13 & \\
\hline
\end{tabular}




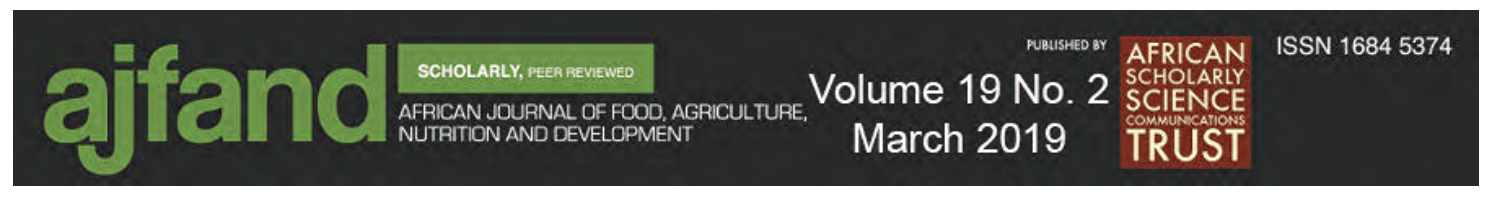

Table 3: Urinary Iodine Concentration $(\mu \mathrm{g} / \mathrm{L})$ in Non-Pregnant Women, Kenya 2011

\begin{tabular}{|c|c|c|c|c|c|c|c|c|c|}
\hline \multirow[b]{2}{*}{ Category } & \multirow[b]{2}{*}{$\mathrm{n}$} & \multirow[b]{2}{*}{ Median } & \multirow{2}{*}{\multicolumn{2}{|c|}{ IQR }} & \multicolumn{4}{|c|}{ UIC distribution shares $(\%)$} & \multirow{2}{*}{$\begin{array}{l}\chi^{2} \text { and } \\
P \text {-value }\end{array}$} \\
\hline & & & & & $<100$ & $100-299$ & $300-499$ & $\geq 500$ & \\
\hline Age & & & & & & & & & 7.19 \\
\hline$<20 y$ & 119 & 165 & 104 & to 287 & 20 & 61 & 13 & 6 & 0.066 \\
\hline$\geq 20 y$ & 504 & 164 & 97 & to 305 & 27 & 47 & 17 & 9 & \\
\hline Residence & & & & & & & & & 11.85 \\
\hline Rural & 389 & 163 & 90 & to 279 & 30 & 47 & 16 & 8 & 0.008 \\
\hline Urban & 234 & 180 & 125 & to 321 & 18 & 55 & 17 & 10 & \\
\hline Region & & & & & & & & & 127.9 \\
\hline Nairobi & 65 & 252 & 175 & to 402 & 9 & 47 & 30 & 14 & $<0.001$ \\
\hline Central & 76 & 222 & 117 & to 367 & 15 & 51 & 19 & 16 & \\
\hline Coast & 54 & 220 & 133 & to 368 & 10 & 51 & 18 & 21 & \\
\hline Eastern & 91 & 203 & 111 & to 310 & 21 & 49 & 21 & 9 & \\
\hline N/Eastern & 30 & 372 & 231 & to 609 & 0 & 36 & 37 & 27 & \\
\hline Nyanza & 85 & 148 & 86 & to 244 & 32 & 51 & 13 & 4 & \\
\hline Rift Valley & 159 & 138 & 80 & to 165 & 36 & 56 & 7 & 1 & \\
\hline Western & 65 & 98 & 64 & to 172 & 52 & 41 & 7 & 0 & \\
\hline HH wealth & & & & & & & & & 51.4 \\
\hline Poorest & 114 & 163 & 98 & to 384 & 27 & 39 & 22 & 12 & $<0.001$ \\
\hline Next & 130 & 131 & 67 & to 226 & 42 & 46 & 9 & 4 & \\
\hline Middle & 120 & 140 & 98 & to 225 & 25 & 58 & 13 & 5 & \\
\hline Next & 111 & 154 & 105 & to 298 & 23 & 52 & 16 & 8 & \\
\hline Wealthiest & 148 & 202 & 134 & to 359 & 12 & 53 & 22 & 13 & \\
\hline All NPW & 623 & 167 & 98 & to 299 & 26 & 50 & 16 & 9 & \\
\hline
\end{tabular}




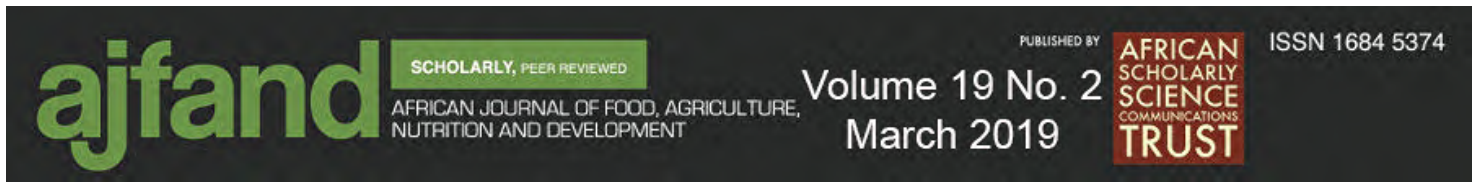

Table 4: Urinary Sodium Concentration $(\mathrm{mmol} / \mathrm{L})$ in School-Age Children, Kenya 2011

\begin{tabular}{|c|c|c|c|c|c|c|c|c|c|}
\hline \multirow[b]{2}{*}{ Category } & \multirow[b]{2}{*}{$\mathrm{n}$} & \multirow[b]{2}{*}{ Mean } & \multirow{2}{*}{\multicolumn{2}{|c|}{$95 \%$ CI }} & \multicolumn{4}{|c|}{ UNaC distribution shares (\%) } & \multirow{2}{*}{$\begin{array}{c}\text { Fisher's F } \\
P \text {-value }\end{array}$} \\
\hline & & & & & $<87$ & $87-174$ & $174-261$ & $\geq 261$ & \\
\hline Age & & & & & & & & & 12.3 \\
\hline 5 to $8 y$ & 386 & 178 & 167 & to 188 & 22 & 32 & 22 & 24 & $<0.001$ \\
\hline 9 to $14 y$ & 477 & 203 & 194 & to 213 & 18 & 21 & 30 & 31 & \\
\hline Gender & & & & & & & & & 21.2 \\
\hline Male & 424 & 209 & 199 & to 219 & 14 & 23 & 28 & 35 & $<0.001$ \\
\hline Female & 439 & 176 & 165 & to 186 & 25 & 28 & 26 & 21 & \\
\hline Residence & & & & & & & & & 22.5 \\
\hline Rural & 635 & 182 & 174 & to 190 & 23 & 25 & 29 & 23 & $<0.001$ \\
\hline Urban & 228 & 221 & 206 & to 235 & 10 & 28 & 21 & 41 & \\
\hline Region & & & & & & & & & 9.55 \\
\hline Nairobi & 45 & 224 & 202 & to 245 & 3 & 31 & 26 & 40 & $<0.01$ \\
\hline Central & 88 & 194 & 174 & to 214 & 13 & 35 & 23 & 29 & \\
\hline Coast & 71 & 241 & 210 & to 272 & 15 & 18 & 21 & 46 & \\
\hline Eastern & 126 & 226 & 208 & to 244 & 10 & 20 & 32 & 38 & \\
\hline N/Eastern & 70 & 210 & 182 & to 238 & 19 & 12 & 38 & 31 & \\
\hline Nyanza & 125 & 184 & 168 & to 200 & 17 & 28 & 33 & 21 & \\
\hline Rift Valley & 233 & 171 & 157 & to 185 & 26 & 30 & 22 & 22 & \\
\hline Western & 104 & 146 & 128 & to 165 & 36 & 25 & 23 & 16 & \\
\hline HH wealth & & & & & & & & & 11.4 \\
\hline Poorest & 224 & 180 & 167 & to 193 & 19 & 27 & 36 & 17 & $<0.001$ \\
\hline $\mathrm{HHW}=2$ & 234 & 164 & 150 & to 178 & 32 & 25 & 19 & 25 & \\
\hline Middle & 189 & 203 & 189 & to 218 & 19 & 21 & 27 & 33 & \\
\hline $\mathrm{HHW}=4$ & 125 & 217 & 199 & to 236 & 7 & 35 & 25 & 32 & \\
\hline Wealthiest & 90 & 236 & 213 & to 260 & 8 & 23 & 25 & 45 & \\
\hline All SAC & 863 & 192 & 185 & to 199 & 20 & 26 & 27 & 28 & \\
\hline
\end{tabular}




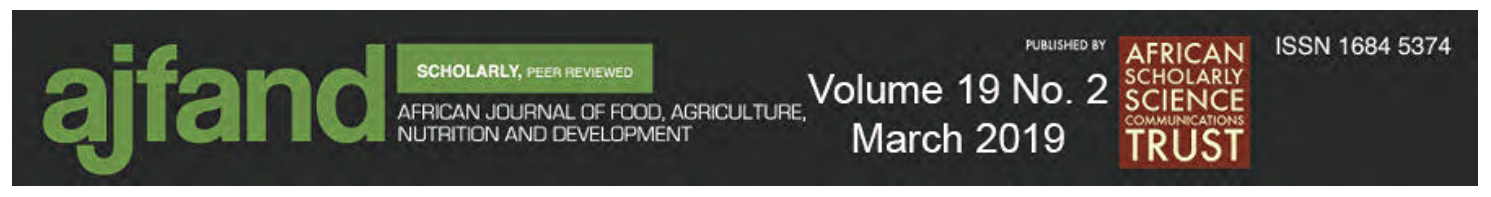

Table 5: Urinary Sodium Concentration (mmol/L) in Non-Pregnant Women, Kenya 2011

\begin{tabular}{|c|c|c|c|c|c|c|c|c|c|}
\hline \multirow[b]{2}{*}{ Category } & \multirow[b]{2}{*}{$\mathrm{n}$} & \multirow[b]{2}{*}{ Mean } & \multirow{2}{*}{\multicolumn{2}{|c|}{$95 \% \mathrm{CI}$}} & \multicolumn{4}{|c|}{ UNaC distribution shares (\%) } & \multirow{2}{*}{$\begin{array}{c}\text { Fisher's F } \\
P \text {-value }\end{array}$} \\
\hline & & & & & $<87$ & $87-174$ & $174-261$ & $\geq 261$ & \\
\hline$<20 y$ & 108 & 218 & 201 & to 236 & 11 & 19 & 35 & 35 & $<0.001$ \\
\hline$\geq 20 y$ & 470 & 178 & 169 & to 187 & 19 & 29 & 31 & 21 & \\
\hline Residence & & & & & & & & & 12.5 \\
\hline Rural & 361 & 175 & 164 & to 185 & 22 & 30 & 29 & 20 & $<0.001$ \\
\hline Urban & 218 & 204 & 192 & to 215 & 11 & 24 & 37 & 29 & \\
\hline Region & & & & & & & & & 12.5 \\
\hline Nairobi & 61 & 231 & 213 & to 249 & 5 & 8 & 53 & 34 & $<0.001$ \\
\hline Central & 71 & 197 & 177 & to 217 & 7 & 37 & 33 & 23 & \\
\hline Coast & 47 & 218 & 187 & to 249 & 16 & 23 & 24 & 36 & \\
\hline Eastern & 84 & 221 & 203 & to 239 & 6 & 18 & 44 & 32 & \\
\hline N/Eastern & 28 & 198 & 157 & to 240 & 4 & 43 & 19 & 34 & \\
\hline Nyanza & 79 & 193 & 169 & to 218 & 19 & 29 & 23 & 28 & \\
\hline Rift Valley & 148 & 149 & 135 & to 163 & 28 & 33 & 29 & 10 & \\
\hline Western & 61 & 125 & 102 & to 149 & 40 & 27 & 22 & 11 & \\
\hline HH wealth & & & & & & & & & 11.3 \\
\hline Poorest & 99 & 186 & 166 & to 206 & 17 & 29 & 31 & 23 & $<0.001$ \\
\hline Next & 131 & 149 & 132 & to 167 & 31 & 30 & 22 & 17 & \\
\hline Middle & 109 & 177 & 160 & to 194 & 20 & 27 & 37 & 16 & \\
\hline Next & 110 & 189 & 171 & to 208 & 16 & 35 & 22 & 27 & \\
\hline Wealthiest & 130 & 226 & 212 & to 240 & 4 & 18 & 45 & 33 & \\
\hline All NPW & 579 & 186 & 178 & to 193 & 18 & 27 & 32 & 23 & \\
\hline
\end{tabular}




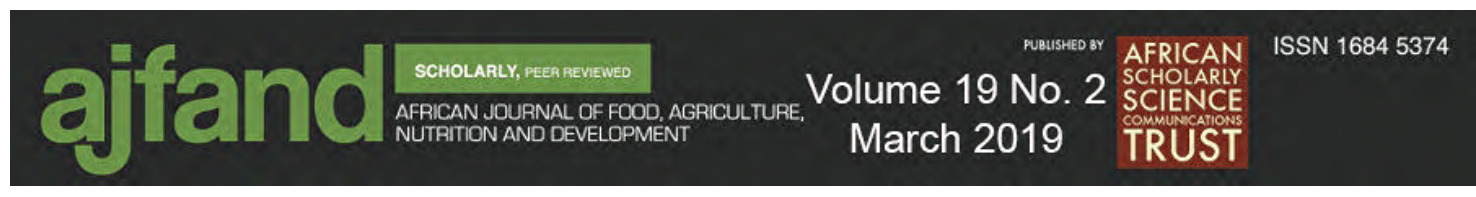

Table 6: Associations of UIC with UNaC, SI and Household Residence by survey group, Kenya 2011

\begin{tabular}{|c|c|c|c|c|c|c|}
\hline \multirow[b]{2}{*}{ GLR Parameters } & \multicolumn{3}{|c|}{ School-age Children $(\mathrm{n}=563)$} & \multicolumn{3}{|c|}{ Non-pregnant Women $(\mathrm{n}=382)$} \\
\hline & Estimate* & $95 \% \mathrm{CI}$ & $P$-value & Estimate* & $95 \% \mathrm{CI}$ & $P$-value \\
\hline Intercept & 4.112 & $3.477,4.747$ & $<0.001$ & 4.158 & $3.848,4.468$ & $<0.001$ \\
\hline $\mathrm{UNaC}(\mathrm{mmol} / \mathrm{L})$ & 0.0044 & $0.0031,0.0057$ & $<0.001$ & 0.0042 & $0.0034,0.0050$ & $<0.001$ \\
\hline $\mathrm{SI}(\mathrm{mg} / \mathrm{kg})$ & 0.0086 & $-0.0030,0.0202$ & 0.14 & 0.0056 & $0.0002,0.0109$ & $<0.05$ \\
\hline \multicolumn{7}{|l|}{ Residence } \\
\hline Rural area & -0.0093 & $-0.2889,0.2703$ & 0.95 & 0.0436 & $-0.0171,0.2585$ & 0.69 \\
\hline Urban area & Reference & - & & Reference & - & \\
\hline
\end{tabular}

* Weighted estimates are the $\beta$-coefficients from GLR with natural log-transformed UIC as the dependent variable

Table 7: UIC portion estimates corresponding with the principle sources of iodine intake by residence in SAC and NPW, Kenya 2011

\begin{tabular}{|c|c|c|c|c|}
\hline \multirow[b]{2}{*}{$\begin{array}{l}\text { Residence type and } \\
\text { source of intake }\end{array}$} & \multicolumn{2}{|c|}{ School-Age Children } & \multicolumn{2}{|c|}{ Non-Pregnant Women } \\
\hline & $\begin{array}{c}\text { Geomean } \\
\text { UIC }(\mu \mathrm{g} / \mathrm{L})^{*}\end{array}$ & $95 \% \mathrm{CI}$ & $\begin{array}{c}\text { Geomean } \\
\text { UIC }(\mu \mathrm{g} / \mathrm{L})^{*}\end{array}$ & $95 \% \mathrm{CI}$ \\
\hline \multicolumn{5}{|l|}{ Rural areas } \\
\hline native iodine & 60.5 & $34.2,86.8$ & 66.8 & $51.1,82.5$ \\
\hline food salt & 86.3 & $48.8,123.8$ & 85.5 & $65.1,105.9$ \\
\hline household salt & 46.8 & $-7.9,101.5$ & 30.4 & $3.1,57.7$ \\
\hline \multicolumn{5}{|l|}{ Urban areas } \\
\hline native iodine & 61.1 & $22.5,99.6$ & 63.9 & $44.2,83.6$ \\
\hline food salt & 87.1 & $32.2,132.1$ & 81.9 & $57.8,105.9$ \\
\hline household salt & 47.2 & $-0.4,94.7$ & 29.1 & $3.5,54.7$ \\
\hline \multicolumn{5}{|l|}{ All areas } \\
\hline native iodine & 60.8 & $29.0,92.6$ & 65.3 & $48.8,81.8$ \\
\hline food salt & 86.7 & $41.3,132.1$ & 83.7 & $63.1,102.2$ \\
\hline household salt & 47.0 & $-3.9,97.8$ & 29.8 & $3.5,56.0$ \\
\hline All Kenya & 194.5 & $145.3,243.6$ & 178.8 & $160.1,197.4$ \\
\hline
\end{tabular}

*UIC values are geometric means, obtained by back-transformation of the natural $\log$ UIC values 


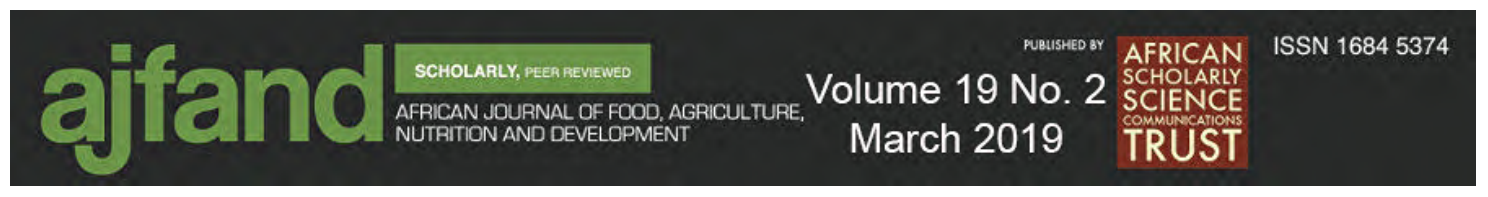

Table 8: Associations of UIC with UNaC, SI, Household Residence and survey group, Kenya 2011

\begin{tabular}{|c|c|c|c|}
\hline GLR Parameters & Estimate* & $95 \% \mathrm{CI}$ & $P$-value \\
\hline Intercept & 4.183 & $3.875,4.491$ & $<0.001$ \\
\hline $\mathrm{UNaC}(\mathrm{mmol} / \mathrm{L})$ & 0.0042 & $0.0034,0.0050$ & $<0.001$ \\
\hline $\mathrm{SI}(\mathrm{mg} / \mathrm{kg})$ & 0.0054 & $-0.0001,0.0110$ & 0.054 \\
\hline \multicolumn{4}{|l|}{ Domain } \\
\hline Rural area & 0.0144 & $-0.1916,0.2204$ & 0.89 \\
\hline Urban area & Reference & - & - \\
\hline \multicolumn{4}{|l|}{ Survey group } \\
\hline SAC & -0.0927 & $-0.5375,0.3521$ & 0.68 \\
\hline NPW & Reference & - & - \\
\hline \multicolumn{4}{|l|}{ Interaction terms } \\
\hline $\mathrm{SAC} \# \mathrm{UNaC}$ & 0.0002 & $-0.0012,0.0016$ & 0.82 \\
\hline SAC \# SI & 0.0032 & $-0.0076,0.0141$ & 0.56 \\
\hline
\end{tabular}

* Weighted estimates are the $\beta$-coefficients from GLR with natural log-transformed UIC as the dependent variable 


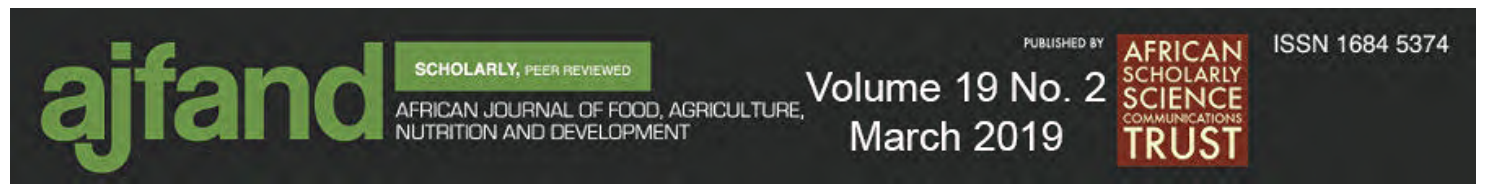

\section{REFERENCES}

1. Redman K, Ruffman T, Fitzgerald $\mathbf{P}$ and $\mathbf{S}$ Skeaff Iodine deficiency and the brain: Effects and mechanisms. Crit Rev Food Sci Nutr 2015; 56(16): 2695-2713.

2. Zimmermann MB, Jooste PL and CS Pandav Iodine-deficiency disorders. The Lancet. 2008; 372: 1251-1262.

3. Andersson M, Karumbunathan $\mathbf{V}$ and MB Zimmermann Global iodine status in 2011 and trends over the past decade. J. Nutr. 2012; 142: 744-750.

4. Hanegraaf TAC Population based studies of endemic goiter. In: Health and Disease in Kenya. East Africa Literature Bureau: Nairobi, Kenya, 1974.

5. Gitau W Review of Iodine Deficiency Disorders in Kenya. E. Afr. Med. J. 1988; 65: 727-733.

6. Ministry of Health, Kenya Medical Research Institute, UNICEF and University of Nairobi Iodine nutrition situation in Kenya and trends in the control of iodine deficiency. Nairobi, Kenya, Mimeo, undated.

7 Government of Kenya Food, Drugs and Chemical Substances Act Special Gazette Notice 9 October 2009

8. Haldimann M, Bochud M, Burnier M, Paccaoud F and V Dudler Prevalence of iodine inadequacy in Switzerland assessed by the estimated average requirement cut-point method in relation to the impact of iodized salt. Publ. Health Nutr. 2015; 18: $1333-1342$.

9. Knowles J, Van der Haar F, Shehata M, Gerasimov G, Bimo B, Cavenagh B, Maramag CC, Otico E, Izwardy D, Spohrer R and GS Garrett Iodine intake through processed food: Case studies from Egypt, Indonesia, the Philippines, the Russian Federation and Ukraine, 2010-2015. Nutrients. 2017; 9:797. doi:10.3390/nu9080979.

10. WHO, UNICEF and ICCIDD Recommended iodine levels in salt and guidelines for monitoring their adequacy and effectiveness. Geneva, Switzerland: WHO, 1996.

11. Whitehead DC The distribution and transformations of iodine in the environment. Environ. Intl. 1984; 10: 321-339.

12. Fordyce FM Database of the iodine content of food and diets populated with data from published literature. Keyworth, Nottingham, UK: British Geological Survey, 2003. 


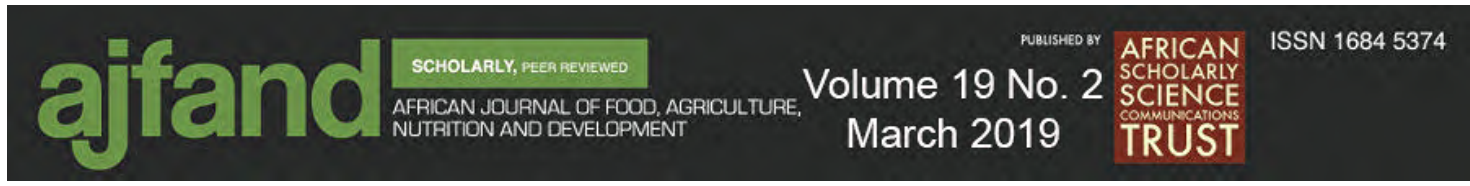

13. WHO, UNICEF and ICCIDD Assessment of iodine deficiency disorders and monitoring their elimination. A guide for programme managers, 3rd Ed. Geneva, Switzerland: WHO, 2008.

14. Santos JA, Webster J, Land M-A, Flood V, Chalmers J, Woodward M, Neal B and KS Petersen Dietary salt intake in the Australian population. Publ. Health Nutr. 2017; May 17: 1-8. doi: 10.1017/S1368980017000799 [Epub ahead of print].

15. Clark AJ and $\mathbf{S}$ Mossholder Sodium and potassium intake measurements. Dietary methodology problems. Am. J. Clin. Nutr. 1986; 43: 470-476.

16. WHO. Reducing salt intake in populations. Report of a WHO Forum and Technical meeting 5-7 October 2006, Paris, France. Geneva, Switzerland: WHO, 2007.

17. Mercado CI, Cogswell ME, Valderrama AL, Wang C-Y, Loria CM, Moshfegh AJ, Rhodes DG and AL Carriquiry Difference between 24-h diet recall and urine excretion for assessing population sodium and potassium intake in adults aged 1839y. Am. J. Clin. Nutr. 2015; 101: 376-386.

18. Stanhewicz AE and WL Kenney Determinants of water and sodium intake and output. Nutr. Rev. 2015; 73(S2): 73-82.

19. Micronutrient Initiative and U.S. Centers for Disease Control and Prevention Micronutrient Survey Toolkit. Ottawa, Canada: Micronutrient Initiative, 2005.

20. Codex Alimentarius Codex Standard for Food-grade Salt, CX STAN 150-1985, Revised in 1997; 2012; Amended in 1999; 2001; 2006. Rome, Italy: Food and Agricultural Organization of the United Nations, 2006. Available at: http://www.fao.org/fao-who-codexalimentarius/shproxy/ar/?lnk=1\&url=https $\% 253 \mathrm{~A} \% 252 \mathrm{~F} \% 252 \mathrm{Fw}$ orkspace.fao.org $\% 252 \mathrm{Fsites} \%$ 252Fcodex $\% 252 \mathrm{FStandards} \% 252 \mathrm{FCODEX} \% 2 \mathrm{BSTAN} \% 2 \mathrm{~B} 150-$ 1985\%252FCXS 150e.pdf. Accessed April 23, 2013.

21. Pino S, Fang SL and LE Braverman Ammonium persulfate: a safe alternative oxidizing reagent for measuring urinary iodine. Clin. Chem. 1996; 42: 239-243.

22. Shimadzu AA-7000 Atomic Absorption Spectrophotometer. Available at: http://www.shimadzu.com/an/elemental/aa/aa7000/aa.html. Accessed April 12, 2013.

23. Sullivan KM, Houston $\mathbf{R}$, Gorstein $\mathbf{J}$ and $\mathbf{J}$ Cervinskas Monitoring universal salt iodization programmes. UNICEF, Programme Against Micronutrient Malnutrition, Micronutrient Initiative, ICCIDD and WHO. Atlanta, 1995. Available at: https://idl-bncidrc.dspacedirect.org/bitstream/handle/10625/13271/107396.pdf?sequence=1 Accessed November 14, 2010. 


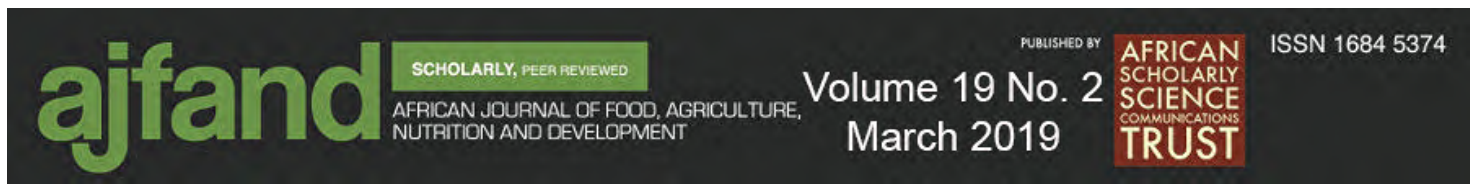

24. Bland JM and DG Altman Measuring agreement in method comparison studies. Stat. Meth. Med. Res. 1999; 8: 135-160.

25. Caldwell KL, Makhmudov A, Jones RL and JG Hollowell EQUIP: A worldwide program to ensure the quality of urinary iodine procedures. Accred. Qual. Assur. 2005; 10: 356-361.

26. Heeringa SG, West BT and PA Berglund Applied Survey Data Analysis. Linear regression models. Boca Raton, FL: CRC Press, 2010; 7: 179-227.

27. Gizak M, Gorstein $\mathbf{J}$ and $\mathbf{M}$ Andersson Epidemiology of iodine deficiency. In: Pearce EN (Ed): Iodine Deficiency Disorders and Their Elimination. Cham, Switzerland: Springer Nature, 2017; 3: 29-43.

28. Reimann C, Bjorvatn K, Frengstad B, Melaku Z, Tekle-Haimanot $\mathbf{R}$ and $\mathbf{U}$ Siewers Drinking water quality in the Ethiopian section of the East African Rift Valley I - Data and health aspects. Sci. Total Environ. 2003; 311: 65-80.

29. Kassim IA, Moloney G, Busili A, Nur AY, Paron P, Jooste P, Gadain H and AJ Seal Iodine intake in Somalia is excessive and associated with the source of household drinking water. J. Nutr. 2014; 144(3): 375-381.

30. Huang L, Crino M, Wu JHY, Woodward M, Land M-A, McLean R, Webster J, Enkhtungalag B and B Neal Mean population salt intake estimated from 24-h urine samples and spot urine samples: A systematic review and meta-analysis. Int. J. Epidemiol. 2016; 45(1): 239-250.

31. Campbell NRC, Correa-Rotter R, Cappuccio FP, Webster J, Lackland DT, Neal $B$ and GA McGregor Proposed nomenclature for salt intake and for reductions in dietary salt. J. Clin. Hypertens. (Greenwich) 2015; 17: 247-251.

32. Rohner F, Zimmermann M, Jooste P, Pandav C, Caldwell K, Raghaven $\mathbf{R}$ and DJ Raiten Biomarkers of nutrition for development - iodine review. J. Nutr. 2014; 144(8): 1322S-1342S.

33. WHO. Guideline: Fortification of food-grade salt with iodine for the prevention and control of Iodine Deficiency Disorders. Geneva, Switzerland: WHO, 2014.

34. Ristic-Medic D, Piskackova Z, Hooper L, Rupric J, Casgrain A, Ashton K, Pavlovic $M$ and $M$ Glibetic Methods of assessment of iodine status in humans: A systematic review. Am. J. Clin. Nutr. 2009; 89: 2052S-2069S.

35. Edwards DG, Kaye AE and E Druce Sources and intakes of sodium in the United Kingdom diet. Eur. J. Clin. Nutr. 1989; 43: 855-861.

36. Mattes RD and D Donelly Relative contributions of dietary sodium sources. $J$. Am. Coll. Nutr. 1991; 10: 383-393. 


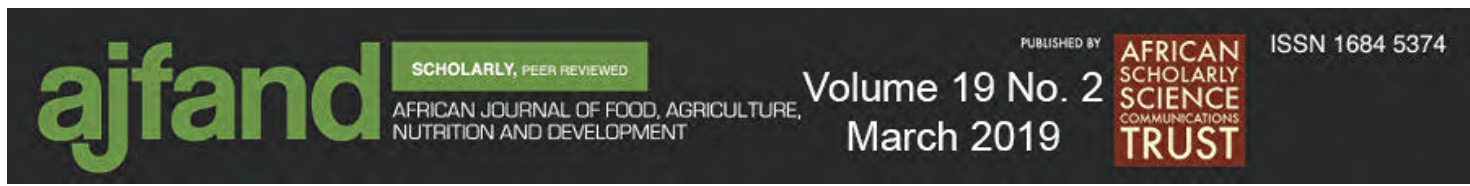

37. FAO. Nutrition country profiles, Kenya. Rome, Italy: Food and Agriculture Organization of the United Nations, undated. Available at:

http://www.fao.org/ag/agn/nutrition/profiles_by_country_en.stm. Accessed May 09, 2017.

38. McLean R Measuring population sodium intake: A review of methods. Nutrients 2014; 6: 4651-4662.

39. Mente A, O'Donnell MJ and S Yusuf Measuring sodium intake in populations: Simple is best? Am. J. Hypertens. 2015; 28(11): 1303-1305.

40. Hawkes $\mathbf{C}$ and $\mathbf{J}$ Webster National approaches to monitoring population salt intake: A trade-off between accuracy and practicality? Plos One 2012; 10: e46727.

41. Cogswell ME, Maalouf J, Elliott P, Loria CM, Patel S and BA Bowman Use of urine biomarkers to assess sodium intake: Challenges and opportunities. Ann. Rev. Nutr. 2015; 35: 349-387.

42. Zimmermann MB, Hussein I, Al Ghannami S, El Badawi S, Al Hamad NM, Hajj BA, Al-Thani M, Al-Thani AA, Winichagoon P, Pongcharoen T, Van der Haar F, Qing-Zhen J, Dold S, Andersson $M$ and AL Carriquiry Estimation of the prevalence of deficient and excessive iodine intakes in school-age children from the adjusted distribution of urinary iodine concentrations from population surveys. J. Nutr. 2016; 146: 1204-1211.

43. White E, Armstrong BK and R Saracci Principles of Exposure Measurement in Epidemiology, $2^{\text {nd }}$ Ed. Exposure measurement error and its effects. Oxford, UK: Oxford University Press, 2008; 3: 65-95.

44. WHO. Global Action Plan for the Prevention and Control of Noncommunicable Diseases 2013-2020. Geneva, Switzerland: WHO, 2013.

45. Poulter NR, Khaw KT, Hopwood BEC, Mugambi M, Peart WS, Rose G and PS Sever The Kenyan Luo migration study: Observations on the initiation of a rise in blood pressure. Brit. Med. J. 1990; 300: 967-972.

46. Powles J, Fahimi S, Micha R, Khatibzadeh S, Shi P, Ezzatti M, Engell RE, Lim SS, Danaei G and D Mozzafarian Global, regional and national sodium intakes in 1990 and 2010: A systematic analysis of 24h urinary sodium excretion and dietary surveys worldwide. BMJ Open. 2013; 3: e003733.

47. Conkle $\mathbf{J}$ and $\mathbf{F}$ van der Haar The use and interpretation of sodium concentrations in casual (spot) urine collections for population surveillance and partitioning of dietary iodine intake sources. Nutrients. 2016; 9(1): E7. doi:10.3390/nu9010007. 